\title{
Vascular endothelial growth factor-A is expressed both on lymphoma cells and endothelial cells in angioimmunoblastic T-cell lymphoma and related to lymphoma progression
}

\author{
Wei-Li Zhao ${ }^{1, *}$, Samia Mourah ${ }^{2}$, Nicolas Mounier ${ }^{1, \dagger}$, Christophe Leboeuf $^{1, \dagger}$, \\ Marjan Ertault Daneshpouy ${ }^{1}$, Luc Legrès ${ }^{1}$, Veronique Meignin ${ }^{1}$, \\ Eric Oksenhendler ${ }^{3}$, Christine Le Maignin ${ }^{4}$, Fabien Calvo ${ }^{2}$, Josette Brière ${ }^{1}$, \\ Christian Gisselbrecht ${ }^{1}$ and Anne Janin ${ }^{1}$ \\ ${ }^{1}$ ERM-0220, Institut Universitaire d'Hématologie, Université Paris VII; ${ }^{2}$ EM-0334, Laboratoire de \\ Pharmacologie; ${ }^{3}$ Service d'Immuno-Hématologie, Hôpital Saint-Louis, AP-HP, 75475 Paris, France and \\ ${ }^{4}$ Service de Cancérologie, Hôpital Européen Georges Pompidou, AP-HP, 75908 Paris, France
}

\begin{abstract}
Vascular endothelial growth factor-A (VEGF-A), a main stimulator of endothelial cell proliferation, plays an important role on tumor angiogenesis. Angioimmunoblastic T-cell lymphoma (AITL) show the most prominent vascular component among lymphomas and their prognosis is difficult to predict. To assess the clinical significance of VEGF-A in AITL, VEGF-A gene expression was studied in the tumoral lymph nodes of 24 patients using laser microdissection and quantitative polymerase chain reaction. VEGF-A gene was overexpressed in both microdissected lymphoma and endothelial cells. Increased levels of VEGF-A gene expression in lymphoma cells, as in endothelial cells, were related to extranodal involvement and to short survival time. Accordingly, VEGF-A protein expression was also found in both types of cells in lymph nodes and bone marrows with lymphomatous involvement. Triple immunofluorescent labeling on lymph node sections showed that VEGF-A protein and its receptor VEGF-R1 were coexpressed on endothelial cells of microvessels in the areas of lymphoma invasion. In these areas, ultrastructural study showed dystrophic microvessels. Taken together, the value of VEGF-A gene expression as an adverse prognostic marker in AITL should thus be considered. In addition to lymphoma cells themselves, the vascular component, a critical pathologic characteristic in AITL, also contributes to lymphoma progression.
\end{abstract}

Laboratory Investigation (2004) 84, 1512-1519, advance online publication, 16 August 2004; doi:10.1038/labinvest.3700145

Keywords: vascular endothelial growth factor-A; angioimmunoblastic T-cell lymphoma

Vascular endothelial growth factor-A (VEGF-A), an important angiogenic molecule, has direct effect on vascular endothelial cells, stimulates endothelial cell proliferation, migration, and increases vascular permeability. ${ }^{1,2}$ The $V E G F-A$ gene is alternatively

Correspondence: Dr A Janin, MD, PhD, ERM-0220, Institut Universitaire d'Hématologie, Université Paris VII, Hôpital Saint-Louis, 1, Avenue Claude Vellefaux, 75475 Paris Cedex 10, France.

E-mail: anne_janin@yahoo.com

${ }^{*}$ Current address: Department of Hematology, Shanghai Institute of Hematology, Shanghai Rui-Jin Hospital, Shanghai Second Medical University, 200025 Shanghai, China.

"NM and CL contributed equally to this work.

Received 21 February 2004; revised and accepted 18 May 2004; published online 16 August 2004 spliced to yield major isoforms of 121, 165, and 189 amino acids (VEGF121, VEGF165, and VEGF189), which are essential for normal vascular development. $^{3}$ VEGF-A exerts its biological function through tyrosine kinase receptors, mainly as VEGFR1 (Flt-1) and VEGF-R2 (KDR/flk-1).,

VEGF-A plays an essential role in embryogenesis, physiologic angiogenesis, and pathologic angiogenesis, particularly, the neovascularization of solid tumors and hematological malignancies. ${ }^{2}$ In solid tumors, VEGF-A overexpression is associated with increased angiogenesis, tumor growth, and metastasis. ${ }^{6}$ The tumor vessels are structurally heterogeneous and process morphological abnormalities. ${ }^{1,7}$ In lymphoma, VEGF-A mRNA and protein 
expression are also detected. ${ }^{8,9}$ Elevated serum VEGF-A concentration is reported to indicate poor disease outcome in non-Hodgkin's lymphoma patients. ${ }^{10}$ Experimentally, VEGF-A gene overexpression by lymphoma cells resulted in increased angiogenesis and correlated with lymphoma cell engraftment efficiency in severe combined immunodeficiency (SCID) mice. ${ }^{11}$ However, the direct link between cellular VEGF-A and lymphoma progression has not yet been determined in lymphoma patients.

Angioimmunoblastic T-cell lymphoma (AITL) shows the most prominent vascular component among lymphoma. ${ }^{12}$ The clinical outcome of the patients differs considerably, with rapid progression and fatal course in some patients, and durable remission and good prognosis in others. ${ }^{13}$ VEGF-A protein expression has been observed by immunohistochemistry in lymphoma cells of AITL. ${ }^{9}$ AITL thus provides a good model to evaluate the clinical significance of VEGF-A and its relation to lymphoma progression.

\section{Materials and methods}

\section{Patients}

In all, 24 AITL patients, 10 male and 14 female, 33-84-year-old (median 60 years), were included in this study. Histological diagnoses were established according to the WHO classification. ${ }^{14}$ Induction chemotherapy consisted of six cycles of CHOP and CHOP-like regimen followed by consolidation and maintenance chemotherapies as previously reported. ${ }^{15}$ The clinical and biological features of these patients are shown in Table 2.

Reactive lymph node hyperplasia of eight age- and sex-matched patients were referred as controls. Approval was obtained from the Institut Universitaire d'Hématologie-Hôpital Saint-Louis institutional review board. All patients gave accordingly their informed consent.

\section{Tissue Specimen}

Lymph nodes, surgically removed for diagnostic purpose, were immediately cut into three parts: one part was fixed in formaldehyde and further processed for paraffin embedding, another part was snap frozen, and the third part was fixed in $2 \%$ glutaraldehyde and embedded in epoxy resin.

Bone marrow biopsies were performed in all 24 AITL patients and skin biopsies in 11 AITL patients with skin rash.

\section{Laser Microdissection}

Laser microdissection was performed on $7 \mu \mathrm{m}$ lymph node-frozen sections of all 24 AITL and eight reactive hyperplasia. $\mathrm{CD}^{+}$medium-sized lympho- ma cells in AITL sections, CD3 ${ }^{+}$small lymphocytes in interfollicular areas of reactive hyperplasia sections, and CD $34^{+}$endothelial cells in both AITL and reactive hyperplasia sections, were laser microdissected (PALM, Bernried, Germany). A quantitative assessment was achieved by PALM Robo software. For each patient, approximately 1500 lymphoma and 1500 endothelial cells, corresponding to an average surface of 450000 and $280000 \mu \mathrm{m}^{2}$, respectively, were microdissected and catapulted into tubes for RNA extraction.

\section{RNA Extraction and cDNA Synthesis}

Total RNA was extracted using the acid-guanidinium thiocyanate-phenol-chloroform method. ${ }^{16}$ First-strand cDNA was synthesized using Superscript II reverse transcriptase (Invitrogen Corporation, CA, USA) and random hexamers primers (Amersham Biosciences, NJ, USA) according to the manufacturer's instructions.

\section{Real-Time Quantitative PCR}

The primers and probes of VEGF-A, its isoforms VEGF121, VEGF165, and VEGF189, and housekeeping gene $\beta 2$-microglobulin $(\beta 2 \mathrm{M})$ were synthesized as reported. ${ }^{17,18}$

The transcripts that encode for VEGF-A, its isoforms and $\beta 2 \mathrm{M}$ were amplified by PCR using corresponding primers. PCR products were separated on a $3 \%$ agarose gel, bands were purified by the QIAquick Gel Extraction Kit (Qiagen GmbH, Hilden, Germany), and subsequently cloned by TOPO II TA Cloning reagent set pCRII (Invitrogen Corporation, San Diego, CA, USA). Plasmids were purified using the Qiagen Miniprep reagent set (Qiagen), sequenced (PE Applied Biosystems, Warrington, UK), and measured by spectrophotometry. Standard curves for VEGF-A, its isoforms and $\beta 2 \mathrm{M}$ were generated using serial dilutions from $10^{10}$ down to $10^{1}$ copies $/ \mu$ l.

Quantitative PCR was realized on LightCycler instrument using LightCycler-FastStart DNA Hybridization Probes Kit (Roche Molecular Biochemicals, Mannheim, Germany) according to the manufacturer's instructions. The amplification conditions for LightCycler consisted of an initial $8 \mathrm{~min}$ of incubation at $94^{\circ} \mathrm{C}$ for FastStart Taq DNA polymerase activation, followed by 45 cycles of denaturation at $94^{\circ} \mathrm{C}$ for $15 \mathrm{~s}$ and annealing/extension at $60^{\circ} \mathrm{C}$ for $20 \mathrm{~s}$. All experiments were performed in duplicate.

Quantification of PCR products was determined by LightCycler software 3.1, according to the standard curve. The expression levels of VEGF-A and its isoforms were normalized by $\beta 2 \mathrm{M}$ and presented as copies of target gene per $10^{3}$ copies of $\beta 2 \mathrm{M}$. 


\section{Immunohistochemistry}

Immunohistochemical analyses were carried out on 5 - $\mu \mathrm{m}$-paraffin sections with an indirect immunoperoxidase method, using antibodies directed against VEGF-A (mouse anti-human VEGF-A antibody, Santa Cruz Biotechnology, Santa Cruz, CA, USA) at 1:100 dilution, VEGF-R1 (goat anti-human VEGF-R1 antibody, kindly provided by Jean Plouet, Institut de Pharmacologie et Biologie Structurale, UMR CNRS 5089, Toulouse, France) at 1:100 dilution, and VEGF-R2 (goat anti-human VEGF-R2 antibody, R\&D Systems Inc., MN, USA) at 1:10 dilution.

\section{Triple Immunofluorescent Labeling}

Triple immunofluorescent labelings were performed on $5-\mu \mathrm{m}$-frozen sections in lymphomatous areas of lymph nodes. The slides were incubated with the antibodies directed against CD34 (rabbit anti-human CD34 antibody, Santa Cruz Biotechnology), VEGF-A, and VEGF-R1 at 1:100 dilution, or CD3 (rabbit anti-human CD3 antibody, Zymed Laboratories, San Francisco, CA, USA), VEGF-A, and VEGF-R1 at 1:100 dilutions. Subsequently, the slides were incubated with FITC-conjugated swine anti-rabbit IgG (DAKOCytomation, Denmark), AMCA-conjugated horse anti-mouse IgG (Vector Laboratories, Burlingame, CA, USA), and rhodamin-conjugated donkey anti-goat IgG (Rockland Immunochemicals, Gilbertsville, PA, USA) at 1:100 dilutions. The number of lymphoma cells, or of vascular sections with endothelial cells coexpressing VEGF-A and VEGF-R1 was assessed by systematic count of three different fields at magnification 400 , for each case.

\section{Electron Microscopy}

Lymph node samples fixed in $2 \%$ glutaraldehydebuffered $0.1 \mathrm{M}$. cacodylate were embedded in epoxy resin. Semithin sections were stained with $2 \%$ toluidine blue, and ultrathin sections with uranyl acetate lead. The analysis focused on microvessels, with emphasis on endothelial cells, basal membranes, and pericytes. Presence or absence, dystrophy or damage of these structures was noted.

\section{Statistical Analyses}

Patient characteristics were compared using $\chi^{2}$ and Fisher's exact tests for categorical variables, and Wilcoxon's test for continuous variables. Event-free survival (EFS) was calculated from the date of diagnosis to the date of progression, relapse, or death. Overall survival (OS) was measured from the date of diagnosis to either death from any cause or the stopping date of January 1, 2003. Survival rates were estimated using the Kaplan-Meier method and compared by log-rank test. Multivariate survival analysis was performed using a Cox regression model. Difference were considered significant when the two-sided $P$-value was $<0.05$. All statistical analyses were performed using SAS 8.2 software (SAS Institute Inc, Cary, NC, USA).

\section{Results}

Overexpression of $V E G F-A$ Gene and Its Isoforms in Both Microdissected Lymphoma and Endothelial Cells in AITL

Compared to reactive hyperplasia, $V E G F-A$ gene was overexpressed in microdissected lymphoma cells in AITL $(P=0.0006)$. Isoforms VEGF121 and VEGF165, but not VEGF189, were significantly increased $(P=0.0009$ and 0.0048 , respectively) (Table 1$)$.

VEGF-A, VEGF121, and VEGF165 levels were also significantly higher in microdissected endothelial cells in AITL than in microdissected endothelial cells from reactive hyperplasia $(P=0.0012,0.0040$, and 0.0131 , respectively) (Table 1 ).

\section{VEGF-A Gene Overexpression Related to Poor Disease Outcome in AITL Patients}

$V E G F-A$ gene overexpression in both lymphoma and endothelial cells was significantly associated with advanced Ann Arbor stage, presence of bone marrow involvement, presence of skin involvement, and high-risk international prognostic index (Table 2).

Within a median follow-up of 51 months, 14 patients $(58 \%)$ relapsed and 12 of them $(50 \%)$ died. The 2-year EFS and OS rate were, respectively, 39.2 and $69.1 \%$, with median EFS and OS at 17 and 38 months. Poor EFS and OS were correlated with high VEGF-A levels, in microdissected lymphoma cells $(P=0.0078$ and 0.0091 , respectively), and in microdissected endothelial cells $(P=0.0152$ and 0.0342 , respectively). Multivariate analyses revealed that VEGF-A levels in microdissected lymphoma cells were independent adverse prognostic factors for EFS and OS ( $P=0.0160$ and 0.0118 , respectively).

\section{VEGF-A and Its Receptor VEGF-R1 Protein were Expressed in Lymph Node and Bone Marrow Sections of AITL}

To assess whether VEGF-A gene was biologically functional, immunohistochemical analyses were performed on lymph nodes and bone marrow specimens, using antibody directed against the VEGF-A protein and two receptors VEGF-R1 and VEGF-R2. VEGF-A protein was expressed in lymphoma cells, as in endothelial cells (Figure 1). Moreover, VEGF-A protein was expressed in the 24 AITL lymph nodes and in the 15 bone marrow biopsies with $\mathrm{CD}^{+}$medium-sized lymphoma cells involvement, but not in the nine bone marrows without lymphoma involvement. The distribution of 
VEGF-A protein expression corresponded to nodal and extranodal invasion by lymphoma in the 24 patients.

VEGF-R1 was also expressed on lymphoma cells as on endothelial cells in lymph node and in bone marrows with $\mathrm{CD}^{+}$medium-sized lymphoma cells involvement. The staining for VEGF-R1 was particularly strong in the areas of adipose tissue invasion in lymph node sections (Figure 1). However, we failed to detect VEGF-R2 expression in the same areas.

\section{VEGF-A and Its Receptor VEGF-R1 Protein were Coexpressed on Endothelial Cells and on Lymphoma Cells in the Areas of Lymphoma Invasion}

In order to determine if lymphoma cells and/or endothelial cells coexpressed VEGF-A and VEGFR1, we performed a triple immunofluorescent labeling on lymph node sections, combining antibodies against CD3, VEGF-A and VEGF-R1, or CD34, VEGF$A$ and VEGF-R1. In the areas of adipose tissue invasion by lymphoma, endothelial cells of the microvessels coexpressed VEGF-A and VEGF-R1 (Figure 2). Quantitative assessment showed that a mean of $46 \%$ (range $38-51 \%$ ) of vascular sections coexpressed the two markers, when a mean of $33 \%$ (range 25-38\%) of lymphoma cells coexpressed them.

\section{Presence of Dystrophic Vessels without Pericytes in the Areas of Lymphoma Invasion}

On lymph node sections, electron microscopy study in the areas of the adipose tissue invasion showed the coexistence of normal microvessels with both endothelial cells and pericytes, and of dystrophic vessels with absence of pericytes. In these dystrophic vessels, endothelial cells were either normal, even turgescent, or thinned and compacted along their basal membrane (Figure 2).

\section{Discussion}

VEGF-A is an important angiogenic cytokine with critical roles in tumor angiogenesis. ${ }^{6}$ In lymphoma, to our knowledge, only experimental data are available for $V E G F-A$ gene expression: VEGF-A and isoforms VEGF121 and VEGF165 were expressed in cell lines of cutaneous T-cell lymphoma and Burkitt's lymphoma. ${ }^{8}$ Using in situ hybridization, Foss et $a l^{19}$ detected VEGF mRNA expression in peripheral T-cell lymphoma (including five AITL); however, double immunolabeling showed that VEGF was mainly observed in reactive nonlymphoid CD68-negative cells. Using laser microdissection and quantitative PCR, we demonstrated that lymphoma cells in AITL overexpressed VEGF-A mRNA, and the same two 
Table 2 VEGF-A gene expression in microdissected lymphoma and endothelial cells according to clinical characteristics in angioimmunoblastic T-cell lymphoma patients $(n=\mathbf{2 4})$

\begin{tabular}{|c|c|c|c|c|c|c|}
\hline \multirow[t]{2}{*}{ Characteristics } & & \multirow[t]{2}{*}{ No. (\%) } & \multicolumn{2}{|c|}{$\begin{array}{l}\text { VEGF- } A^{\mathrm{a}} \text { Microdissected } \\
\text { lymphoma cells }\end{array}$} & \multicolumn{2}{|c|}{$\begin{array}{l}V E G F-A^{\text {a }} \text { Microdissected } \\
\text { endothelial cells }\end{array}$} \\
\hline & & & $\mathrm{X}($ s.d.) & $\mathrm{P}^{\mathrm{b}}$ & $\mathrm{X}($ s.d.) & $\mathrm{P}^{\mathrm{b}}$ \\
\hline \multicolumn{7}{|l|}{ Clinical features } \\
\hline \multirow[t]{2}{*}{ Age (years) } & $<60$ & $12(50)$ & 3.66 (1.39) & 0.4456 & $6.44(2.19)$ & 0.1277 \\
\hline & $>60$ & $12(50)$ & $4.35(1.88)$ & & $8.63(3.09)$ & \\
\hline \multirow[t]{2}{*}{ Gender } & Male & $10(42)$ & $4.63(1.65)$ & 0.8371 & $7.63(2.01)$ & 0.8895 \\
\hline & Female & $14(58)$ & $4.43(1.84)$ & & $7.20(2.75)$ & \\
\hline \multirow[t]{2}{*}{ Hepatosplenomegaly } & Yes & $18(75)$ & $4.39(1.79)$ & 0.1320 & $7.95(2.56)$ & 0.3252 \\
\hline & No & $6(25)$ & $2.84(1.17)$ & & $6.30(2.70)$ & \\
\hline \multirow[t]{2}{*}{ ECOG } & $0-1$ & $10(42)$ & $3.59(1.43)$ & 0.4455 & $6.57(2.09)$ & 0.2583 \\
\hline & $2-4$ & $14(58)$ & $4.30(1.73)$ & & $8.23(3.05)$ & \\
\hline \multirow[t]{3}{*}{ Ann Arbor Stage } & II & $2(8)$ & $2.04(0.71)$ & 0.0146 & $3.56(0.65)$ & 0.0104 \\
\hline & III & $6(25)$ & $2.40(0.78)$ & & $4.99(0.78)$ & \\
\hline & IV & $16(67)$ & $4.85(1.78)$ & & $8.99(2.62)$ & \\
\hline \multirow[t]{2}{*}{ B-symptoms } & A & 4 (17) & $2.40(0.96)$ & 0.1076 & $4.99(1.17)$ & 0.1109 \\
\hline & $\mathrm{B}$ & $20(83)$ & $4.32(1.67)$ & & $8.05(2.76)$ & \\
\hline \multirow[t]{2}{*}{ Bone marrow involvement } & Yes & $15(63)$ & $5.16(0.42)$ & $<0.0001$ & $9.49(2.08)$ & $<0.0001$ \\
\hline & No & $9(37)$ & $2.08(0.95)$ & & $4.29(0.96)$ & \\
\hline \multirow[t]{2}{*}{ Skin involvement } & Yes & $8(33)$ & $5.80(1.89)$ & 0.0020 & $9.83(2.51)$ & 0.0200 \\
\hline & No & $16(67)$ & $3.10(1.22)$ & & $6.40(2.42)$ & \\
\hline \multicolumn{7}{|l|}{ International prognostic index } \\
\hline \multirow{2}{*}{\multicolumn{2}{|c|}{$\begin{array}{l}\text { Low risk-intermediate low risk } \\
\text { Intermediate high risk-high risk }\end{array}$}} & 8 (33) & $2.73(0.88)$ & 0.0389 & $5.26(1.58)$ & 0.0202 \\
\hline & & $16(67)$ & $4.64(1.76)$ & & $8.68(2.56)$ & \\
\hline \multicolumn{7}{|l|}{ Biological features } \\
\hline \multirow[t]{2}{*}{ Lactate dehydrogenase } & $<$ Normal & $5(21)$ & $2.87(1.30)$ & 0.1983 & $5.72(0.99)$ & 0.1979 \\
\hline & $>$ Normal & $19(79)$ & $4.30(1.77)$ & & $8.02(2.94)$ & \\
\hline \multirow[t]{2}{*}{ Coomb's test } & Positive & $10(42)$ & $3.65(1.44)$ & 0.3573 & $8.17(3.25)$ & 0.4690 \\
\hline & Negative & $14(58)$ & $2.10(0.36)$ & & $7.09(2.28)$ & \\
\hline \multirow[t]{2}{*}{ Hypereosinophilia } & Yes & $9(38)$ & $2.54(1.12)$ & 0.0558 & $5.76(2.21)$ & 0.0779 \\
\hline & No & $15(62)$ & $4.74(1.64)$ & & $8.43(2.55)$ & \\
\hline \multirow[t]{2}{*}{ Hypergammaglobulinemia } & Yes & $10(42)$ & $3.32(1.97)$ & 0.8188 & $6.74(2.69)$ & 0.8594 \\
\hline & No & $14(58)$ & $3.06(1.07)$ & & $6.68(2.22)$ & \\
\hline
\end{tabular}

${ }^{\mathrm{a}}$ All data presented as copy numbers of target gene per 1000 copy numbers of $\beta 2 \mathrm{M}$.

${ }^{\mathrm{b}} P$-value obtained when comparing the subgroups of each characteristic.

isoforms VEGF121 and VEGF165. Moreover, in this series of AITL, the expression of VEGF-A, VEGF121 and VEGF165 was also significantly increased in microdissected endothelial cells. This confirms that although the malignant cells themselves are primarily responsible for VEGF-A expression in tumors, vascular endothelium may also express VEGF-A. ${ }^{6,20}$

The levels of these three markers, in microdissected lymphoma cells as in microdissected endothelial cells, correlated with adverse clinical prognostic factors and decreased survival time. Particularly, VEGF-A overexpression in lymphoma cells was an independent prognostic factor, suggesting that lymphoma cells play an important role on disease progression. As far as we know, no previous study addressed the prognostic value of VEGF-A gene expression in lymphoma. In acute myeloid ${ }^{21,22}$ and lymphoblastic leukemia, ${ }^{23}$ a direct link between high cellular VEGF-A level and short survival has been reported. In solid tumors, VEGF-A gene overexpression was associated with advanced stage, metastasis, and poor prognosis in lung ${ }^{24}$ and colon cancer. $^{25}$
The correlation we found between high levels of $V E G F-A$ gene and its two isoforms with poor disease outcome could be linked to tissue invasion by lymphoma. The pattern of VEGF-A protein expression, on lymphoma and endothelial cells, is in accordance with $V E G F$ - $A$ gene overexpression in the two cell populations selected from AITL sections by laser microdissection. This suggests the involvement of both the lymphoma and the vascular component of AITL in VEGF-A synthesis and expression. A striking feature in our study was that the distribution of VEGF-A protein expression corresponded to nodal and extranodal involvement by lymphoma in the 24 patients: VEGF-A protein was strongly expressed on lymphoma cells invading perinodal adipose tissue, or bone marrows, while it was not found in bone marrows without lymphoma involvement.

Since VEGF-A exerts its activity through the binding of specific receptors, we studied the expression and distribution pattern of two receptors, VEGF-R1 and VEGF-R2, by immunohistochemistry. VEGF-R1, but not VEGF-R2, was expressed in lymphoma cells and in endothelial cells. As 
VEGF-A
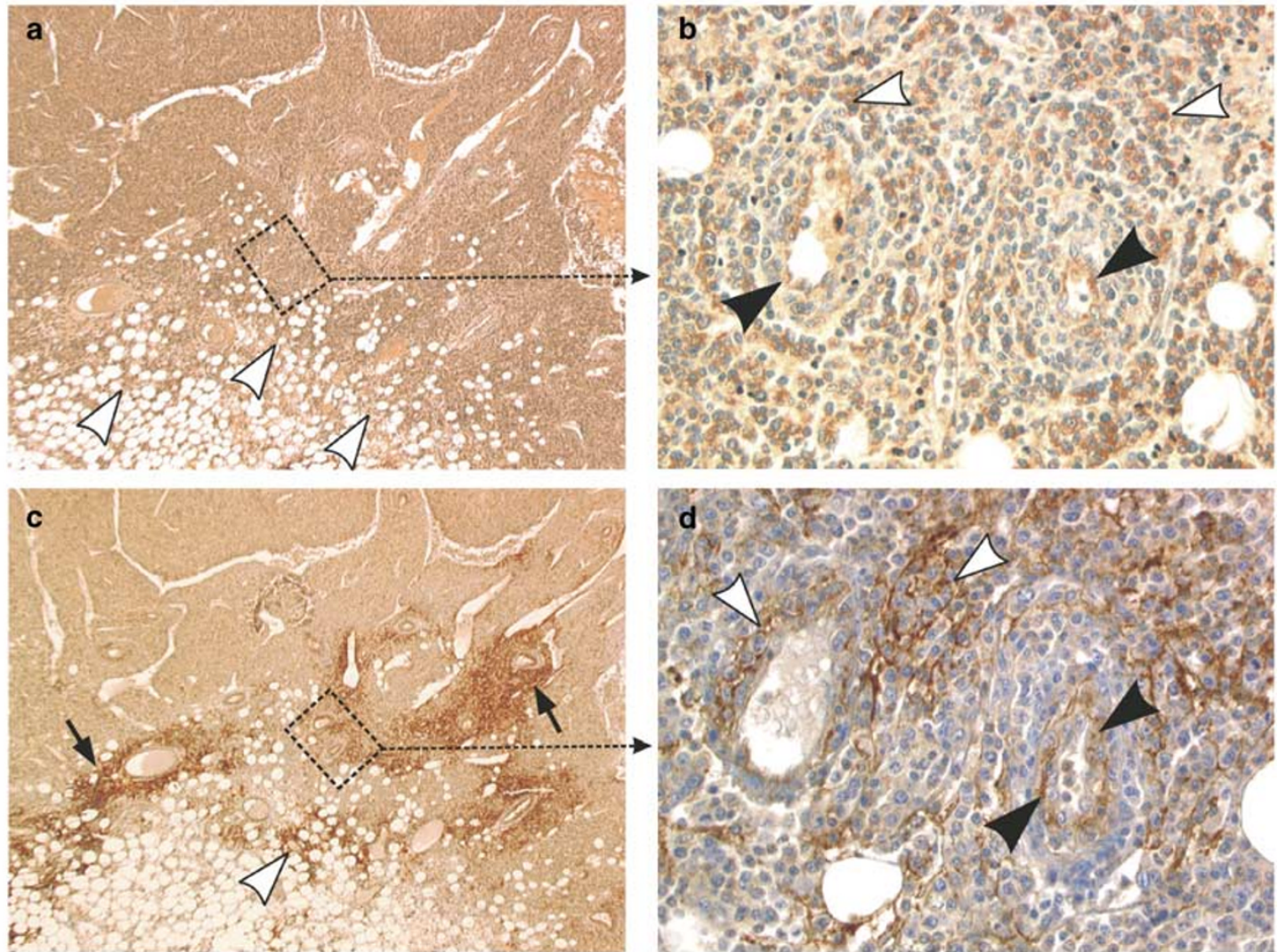

VEGF-R1
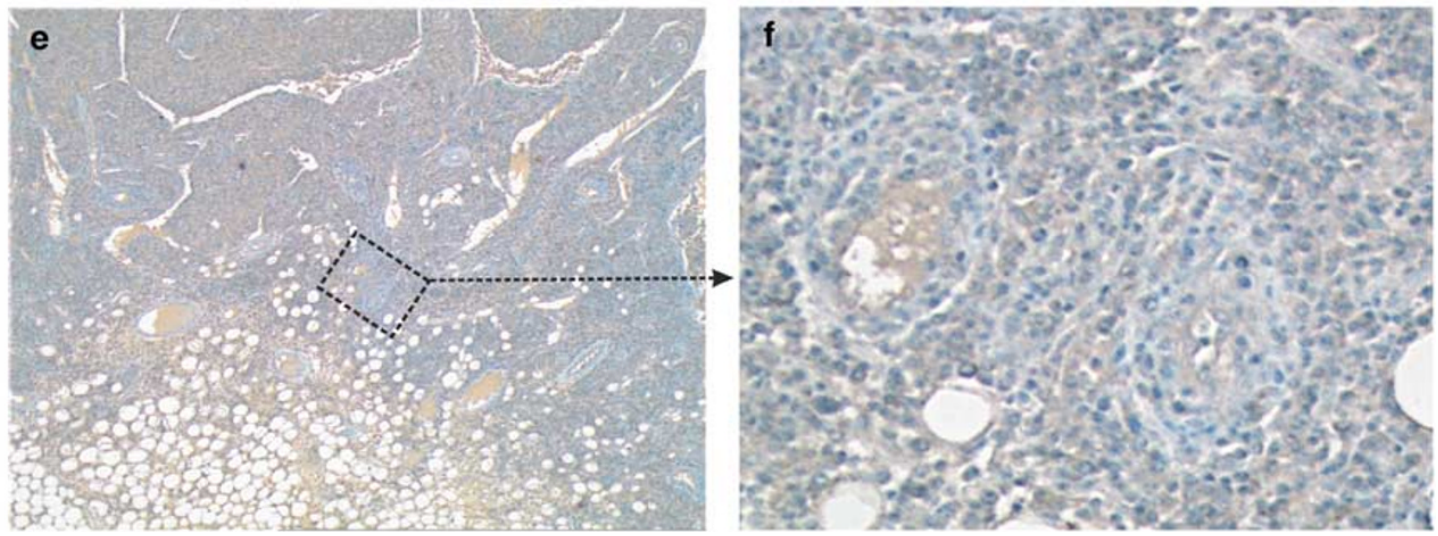

Figure 1 Lymph node of AITL: Immunohistochemical study of the expression of VEGF-A and its receptors (VEGF-R1 and VEGF-R2) on following sections (indirect immunoperoxidase method $(\mathbf{a}, \mathbf{c}, \mathbf{e}, \times 40)$. (b, d, f) corresponded to higher magnification $(\times 400)$ of the lymphomatous areas framed by dotted lines in (a, c, e). (a) VEGF-A was expressed on lymphoma cells invading lymph node capsule and adipose tissue (empty arrowheads), $\times 40$. (b) Higher magnification $(\times 400)$ of the area framed with dotted line in (a): VEGF-A was expressed on lymphoma cells (empty arrowheads) and on endothelial cells of medium-sized vessels (full arrowheads). (c) VEGF-R1 was expressed around vessels (arrows) and on lymphoma cells invading lymph node capsule and adipose tissue (empty arrowheads), $\times 40$. (d) Higher magnification $(\times 400)$ of the area framed with dotted line in (c): VEGF-R1 was expressed on lymphoma cells (empty arrowheads) and on endothelial cells of medium-sized vessels (full arrowheads). (e): VEGF-R2 was not expressed on lymphoma cells or around vessels on the same areas of the following sections, $\times 40$. (f) Higher magnification $(\times 400)$ of the area framed with dotted line in (e): VEGF-R2 was not expressed on endothelial cells of the same vessels as (d).

previously reported, only VEGF-R1 was found in a series of lymphoma cell lines. ${ }^{8}$ In endothelial cells, this could be due to hypoxia, by which VEGF-R1 is selectively induced with VEGF-R2 downregulated. ${ }^{20}$ Interestingly, VEGF-R1 was also detected in the areas of lymphoma invasion in lymph nodes (extension in perinodal adipose tissue) and in bone marrows with lymphoma involvement, where VEGF-A protein was expressed. Using triple immunofluorescent labeling, we proved that VEGF-A and VEGF-R1 were coexpressed on lymphoma cells. In vitro models of T-leukemia cells ${ }^{26}$ and myeloma cells ${ }^{27}$ coexpressing VEGF-A and VEGF-R1 showed that VEGF-A participates in cell migration through 

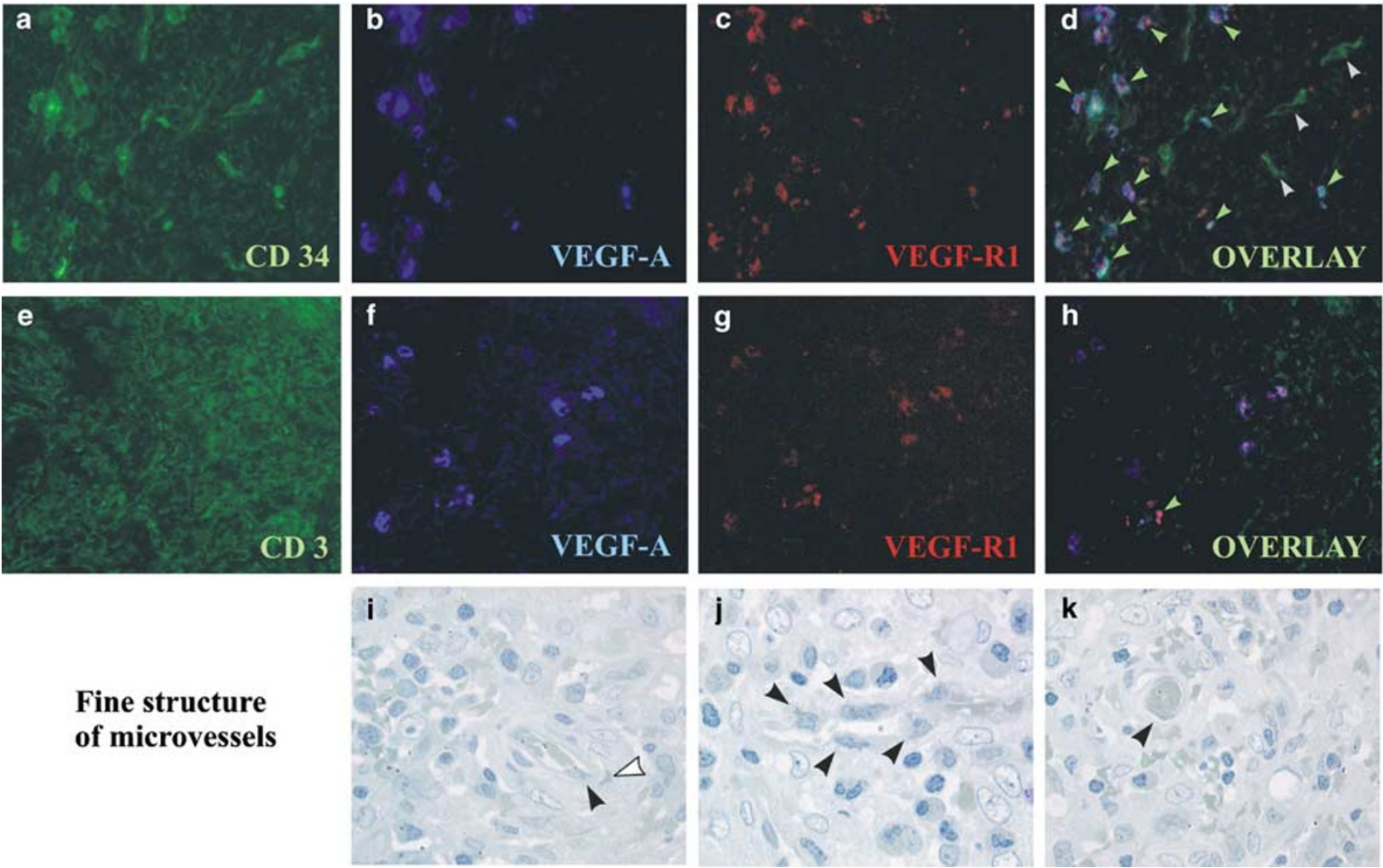

Figure 2 Lymph node of AITL: (a-h) Expression of VEGF-A and VEGF-R1 in the areas of lymphoma invasion, $\times 100$. (i-k) Fine structure of microvessels in semithin sections, $\times$ 800. The combined triple immunofluorescent labeling of CD34 (a), VEGF-A (b) and VEGF-R1 (c) showed that most endothelial cells coexpressed VEGF-A and VEGF-R1 (d) (green arrowheads), when only few endothelial cells identified by fluorescent CD34 staining did not express VEGF-A or VEGF-R1 (white arrowheads). The combined triple immunofluorescent labeling of CD3 (e), VEGF-A (f), and VEGF-R1 (g) showed that many lymphoma cells expressed VEGF-A (f), but only few of them expressed VEGFR1 (g) and coexpressed VEGF-A and VEGF-R1 (h) (green arrowheads). (i) Microvessel with normal structure: endothelial cells (full arrowheads) and pericytes (empty arrowheads). (j) Dystrophic microvessel with turgescent normal endothelial cells (full arrowheads) but no pericyte. (k) Dystrophic microvessel with thinned endothelial cell (full arrowheads) but no pericyte.

activation of VEGF-R1 and facilitate tissue invasion. Importantly, VEGF-A and VEGF-R1 were coexpressed on endothelial cells in areas of lymphoma invasion. Recent experiments have demonstrated the importance of anti-Flt-1 therapy in the inhibition of tumor angiogenesis. ${ }^{28}$ In murine models of lung carcinoma and colorectal carcinoma, VEGF-R1 expression in endothelial cells was significantly related to tumor growth and metastasis. ${ }^{29}$ VEGF-A, both expressed on lymphoma cells and endothelial cells can bind to VEGF-R1 and facilitate lymphoma invasion.

Ultrastructural study showed the microvessels deprived of pericytes in the areas of perinodal adipose tissue invasion in our series of AITL. In solid tumors expressing VEGF-A, as ovarian can$\mathrm{cer}^{30}{ }^{30}$ or glioma, ${ }^{31}$ dystrophic microvessels with pericyte loss were also found within the tumors. Therefore, in this type of lymphoma, the vascular component, and not only the lymphoma cells, could contribute to tumor growth and metastasis.

In conclusion, VEGF-A was both expressed in lymphoma and endothelial cells, and involved in lymphoma progression in these 24 cases of AITL.
Further biological studies are needed to assess if angiogenesis inhibitors could be efficient agents in AITL treatment.

\section{Acknowledgements}

We thank Gérard Socié for critical review of the manuscript, François-louis Plassa and Marie-Pierre Podgorniak for technical assistance, Sylvie Corre and Vivianne Ludosky for data management, and Laboratoire Photo d'Hématologie and Hervé Gautier for illustrations. This work was supported in part by INSERM, Université Paris VII and Association pour la Recherche sur le Cancer (ARC) subvention 9052.

\section{References}

1 Dvorak HF. Rous-Whipple award lecture. How tumors make bad blood vessels and stroma. Am J Pathol 2003;162:1747-1757.

2 Ferrara N, Gerber HP, LeCouter J. The biology of VEGF and its receptors. Nat Med 2003;9:669-676. 
3 Tischer E, Mitchell R, Hartman T, et al. The human gene for vascular endothelial growth factor. Multiple protein forms are encoded through alternative exon splicing. J Biol Chem 1991;266:11947-11954.

4 de Vries C, Escobedo JA, Ueno H, et al. The fms-like tyrosine kinase, a receptor for vascular endothelial growth factor. Science 1992;255:989-991.

5 Terman BI, Dougher-Vermazen M, Carrion ME, et al. Identification of the KDR tyrosine kinase as a receptor for vascular endothelial cell growth factor. Biochem Biophys Res Commun 1992;187:1579-1586.

6 Dvorak HF. Vascular permeability factor/vascular endothelial growth factor: a critical cytokine in tumor angiogenesis and a potential target for diagnosis and therapy. J Clin Oncol 2002;20:4368-4380.

7 Gee MS, Procopio WN, Makonnen S, et al. Tumor vessel development and maturation impose limits on the effectiveness of anti-vascular therapy. Am J Pathol 2003;162:183-193.

8 Bellamy WT, Richter L, Frutiger Y, et al. Expression of vascular endothelial growth factor and its receptors in hematopoietic malignancies. Cancer Res 1999;59: 728-733.

9 Stewart M, Talks K, Leek R, et al. Expression of angiogenic factors and hypoxia inducible factors HIF 1, HIF 2 and CA IX in non-Hodgkin's lymphoma. Histopathology 2002;40:253-260.

10 Salven P, Teerenhovi L, Joensuu H. A high pretreatment serum vascular endothelial growth factor concentration is associated with poor outcome in non-Hodgkin's lymphoma. Blood 1997;90:3167-3172.

11 Fusetti L, Pruneri G, Gobbi A, et al. Human myeloid and lymphoid malignancies in the non-obese diabetic/ severe combined immunodeficiency mouse model: frequency of apoptotic cells in solid tumors and efficiency and speed of engraftment correlate with vascular endothelial growth factor production. Cancer Res 2000;60:2527-2534.

12 Frizzera G, Moran EM, Rappaport H. Angio-immunoblastic lymphadenopathy with dysproteinaemia. Lancet 1974;1:1070-1073.

13 Pangalis GA, Moran EM, Nathwani BN, et al. Angioimmunoblastic lymphadenopathy. Long-term follow-up study. Cancer 1983;52:318-321.

14 Harris NL, Jaffe ES, Diebold J, et al. Lymphoma classification-from controversy to consensus: the R. E.A.L. and WHO Classification of lymphoid neoplasms. Ann Oncol 2000;11:3-10.

15 Pautier P, Devidas A, Delmer A, et al. Angioimmunoblastic-like T-cell non Hodgkin's lymphoma: outcome after chemotherapy in 33 patients and review of the literature. Leuk Lymphoma 1999;32:545-552.

16 Chomczynski P, Sacchi N. Single-step method of RNA isolation by acid guanidinium thiocyanate-phenolchloroform extraction. Anal Biochem 1987;162: 156-159.

17 Wellmann S, Taube T, Paal K, et al. Specific reverse transcription-PCR quantification of vascular endothelial growth factor (VEGF) splice variants by LightCycler technology. Clin Chem 2001;47:654-660.

18 Menashi S, Serova M, Ma L, et al. Regulation of extracellular matrix metalloproteinase inducer and matrix metalloproteinase expression by amphiregulin in transformed human breast epithelial cells. Cancer Res 2003;63:7575-7580.

19 Foss HD, Araujo I, Demel G, et al. Expression of vascular endothelial growth factor in lymphomas and Castleman's disease. J Pathol 1997;183:44-50.

20 Detmar M, Brown LF, Berse B, et al. Hypoxia regulates the expression of vascular permeability factor/vascular endothelial growth factor (VPF/VEGF) and its receptors in human skin. J Invest Dermatol 1997;108: 263-268.

21 Aguayo A, Estey E, Kantarjian H, et al. Cellular vascular endothelial growth factor is a predictor of outcome in patients with acute myeloid leukemia. Blood 1999;94:3717-3721.

22 de Bont ES, Fidler V, Meeuwsen T, et al. Vascular endothelial growth factor secretion is an independent prognostic factor for relapse-free survival in pediatric acute myeloid leukemia patients. Clin Cancer Res 2002;8:2856-2861.

23 Koomagi R, Zintl F, Sauerbrey A, et al. Vascular endothelial growth factor in newly diagnosed and recurrent childhood acute lymphoblastic leukemia as measured by real-time quantitative polymerase chain reaction. Clin Cancer Res 2001;7: 3381-3384.

24 Yuan A, Yu CJ, Chen WJ, et al. Correlation of total VEGF mRNA and protein expression with histologic type, tumor angiogenesis, patient survival and timing of relapse in non-small-cell lung cancer. Int J Cancer 2000;89:475-483.

25 Tokunaga T, Oshika Y, Abe Y, et al. Vascular endothelial growth factor (VEGF) mRNA isoform expression pattern is correlated with liver metastasis and poor prognosis in colon cancer. $\mathrm{Br} \mathrm{J}$ Cancer 1998;77:998-1002.

26 Hayashibara T, Yamada Y, Miyanishi T, et al. Vascular endothelial growth factor and cellular chemotaxis: a possible autocrine pathway in adult T-cell leukemia cell invasion. Clin Cancer Res 2001;7:2719-2726.

27 Podar K, Tai YT, Davies FE, et al. Vascular endothelial growth factor triggers signaling cascades mediating multiple myeloma cell growth and migration. Blood 2001;98:428-435.

28 Luttun A, Tjwa M, Moons L, et al. Revascularization of ischemic tissues by PlGF treatment, and inhibition of tumor angiogenesis, arthritis and atherosclerosis by anti-Flt1. Nat Med 2002;8:831-840.

29 Pavco PA, Bouhana KS, Gallegos AM, et al. Antitumor and antimetastatic activity of ribozymes targeting the messenger RNA of vascular endothelial growth factor receptors. Clin Cancer Res 2000;6: 2094-2103.

30 Zhang L, Yang N, Park JW, et al. Tumor-derived vascular endothelial growth factor up-regulates angiopoietin-2 in host endothelium and destabilizes host vasculature, supporting angiogenesis in ovarian cancer. Cancer Res 2003;63:3403-3412.

31 Benjamin LE, Golijanin D, Itin A, et al. Selective ablation of immature blood vessels in established human tumors follows vascular endothelial growth factor withdrawal. J Clin Invest 1999;103:159-165. 